\title{
International variation in perceiving goals of a youth development programme (Lions Quest)
}

\section{Talvio, Markus}

2013-11-13

Talvio , M \& Lonka , K 2013, ' International variation in perceiving goals of a youth development programme (Lions Quest) ' , The European Journal of Social \& Behavioural Sciences , vol. 6 , no. 3 , pp. 1057-1065 . https://doi.org/10.15405/ejsbs.82

http://hdl.handle.net/10138/232975

https://doi.org/10.15405/ejsbs.82

cc_by_nc_nd

publishedVersion

Downloaded from Helda, University of Helsinki institutional repository.

This is an electronic reprint of the original article.

This reprint may differ from the original in pagination and typographic detail.

Please cite the original version. 


\title{
The European Journal of Social \& Behavioural Sciences (EJSBS)
}

\section{International variation in perceiving goals of a youth development programme (Lions Quest)}

\author{
Markus Talvio $^{\mathrm{a} *}$, Kirsti Lonka ${ }^{\mathrm{a}}$ \\ ${ }^{\mathrm{a}}$ University of Helsinki, P.O. Box 9, 00014 University of Helsinki, Finland
}

http://dx.doi.org/10.15405/ejsbs.82

\begin{abstract}
We investigated the perceptions of the implementers' goals of an international social and emotional learning (SEL) programme, Lions Quest (LQ). Data were collected from 22 trainers and country directors representing 15 countries who had implemented LQ in their country. The answers were content analysed and categorized and then compared qualitatively with the original goals of the LQ programme. The perceived goals of the LQ implementers were quite similar to the original goals. However, drug and alcohol prevention or service to others was mentioned by only a few participants although they were the original goals of LQ.
\end{abstract}

(C) 2013 Published by C-crcs. Peer-review under responsibility of Editor or Guest Editor of the EJSBS.

Keywords: social and emotional learning (SEL) ; teacher training ; prevention ; Lions Quest (LQ) ; service learning

\footnotetext{
* Markus Talvio Tel: +358451341634

E-mail address: mtalvio@gmail.com
}

\section{Introduction}

Cultural sensitivity is one of the quality criteria of programmes on social and emotional learning (SEL) (Collaborative of Academic, Social and Emotional Learning, 2002). When students with various cultural backgrounds enter the SEL workshop it is important that their experiences are beneficial so that they can anchor the outcomes of the workshop to their life. Hence, when adapting the SEL programme to a new country, local circumstances including values and customs should be taken into consideration. However, international SEL

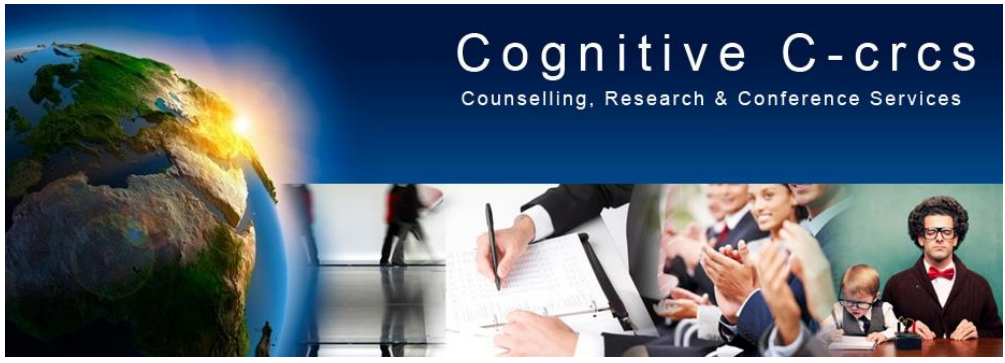


programmes are often registered trademark products including the requirement to obey predefined principles and goals so that they can be identified as the same programme. Thus, recommendations about cultural sensitivity might remain unfulfilled because of certain agreements between the implementer and the owner of the programme.

Lions Quest (LQ) is a registered trademark SEL programme organized for teachers in 80 countries. More than 500,000 educators have been trained to implement the LQ programmes (Lions Clubs International, 2013a). When LQ is adopted in a new country, it is implemented through the local trainers and country directors who are trained and supported by the LQ headquarters. At a national level, trainers adjust the original LQ curricula to the local circumstances and conduct LQ teachers' workshops in their own country. Country directors, in turn, are responsible for organizing resources for marketing and financing. Thus, it depends to a large extent on these two groups what the course is like in a particular country. At present, the length of the teachers' workshop varies from one to three days depending on the country. In addition, the content of the teacher's manual varies from country to country.

The current study is part of a larger evaluation project on the outcomes of LQ. To be able to compare them in different countries, it is essential first to compare the perceptions on LQ goals of these two key groups. Only if their perceived goals on LQ are similar in different countries can we compare the outcomes of the LQ training later on. In this study we investigated if the original goals of the multinational LQ programme differ from the perceived goals of the national LQ executors and whether there was variation internationally.

\subsection{Social and emotional learning (SEL) and substance abuse prevention behind the LQ programme}

Social and emotional learning (SEL), first introduced in 1994, is a conceptual framework including core components, namely self-awareness, self-management, social awareness, relationship skills and responsible decision making (Elias et al., 1997). According to Greenberg et al. (2003), the roots of the framework of SEL are found in young people's health promotion and prevention. The perceived ineffectiveness of diverse educational efforts on, for example, drug and alcohol prevention, spurred a meeting of school-based education researchers, teachers and advocates. They created a framework of SEL to address the underlying causes of problem behaviour rather than targeting a specific problem (Greenberg et al., 2003). Based on the foundation of the SEL framework, a new nonprofit organization, the Collaborative for Academic, Social, and Emotional Learning (CASEL), was established, which works to advance both the science and evidence-based practice of SEL and strengthen the field and impact of SEL (Collaborative for Academic, Social, and Emotional Learning, 2013; Greenberg et al., 2003).

SEL is based on the idea that learning can be improved by enhancing the relationships in the learning context (Elbertson, Brackett, \& Weissberg, 2010). Two groups of theoretical models comprise the SEL framework (Payton et al., 2000). First, theoretical models of social and emotional learning consist of theories of emotional intelligence (Mayer \& Salovey, 1997), social and emotional competence promotion (Haggerty, Sherrod, Garmezy, \& Rutter, 1994), the social developmental model (Hawkins, 1997), social information processing (Crick \& Dodge, 1994), and self-management (Kanfer \& Goldstein, 1991). Second, learning theories and behaviour change comprise Problem Behaviour Theory (Jessor, 1992), Social-Cognitive Theory (Bandura, 1998) and the Theory of Reasoned Action (Azjen \& Fishbein, 1980).

Considerable research has been carried out on the effects of SEL programmes on pupils (i.e. Durlak \& Wells, 1997; Catalano, Berglund, Ryan, Lonczak, \& Hawkins, 2004; Greenberg et al., 2003; Wells, Barlow, \& StewartBrown, 2003; Zins, Weissberg, Wang, \& Walberg, 2004; Brock, Nishida, Chiong, Grimm, \& Rimm-Kaufman, 2008; Rimm-Kaufman, Fan, Chiu, \& You, 2007; Rimm-Kaufman, 2006). Durlak, Weissberg, Dymnicki, Taylor, and Schellinger (2011) reported a meta-analysis of 213 evaluations on pupils ranging in ages from 5 to 18 who attended the SEL programme. Overall, significant positive effects on the targeted socio-emotional competencies and attitudes about the self, others and school were found. In addition, SEL interventions enhanced students' behavioural adjustment in the form of increased pro-social behaviours and reduced behavioural problems. Further, SEL programmes yielded improved academic performance in achievement tests and grades.

There is also a great deal of research available on the effectiveness of preventive programmes. In their review, Thomas, McLellan and Perera (2013) investigated the effectiveness of smoking prevention programmes. Altogether, 134 studies involving over 400,000 students were found. The authors concluded that those programmes that used the 
social competence approach and those that combined a social competence with a social influence approach were found to be more effective than other programmes (Thomas, McLellan \& Perera, 2013). Cuijpers (2002) investigated studies on drug prevention programmes in his review article. As a result of this study he formulated quality criteria for the prevention programmes. In order to strengthen the effects of the programme one suggestion in the criteria was to add life skills to the content of the programmes. Interactive learning methods were also suggested. Further, in research regarding the use of fear in substance abuse preventive field (Prevention First, 2008) it was concluded that scare tactics or causing fear were not found to be effective in preventing or producing sustained reductions of alcohol, tobacco or drug use among youth. In spite of the above-mentioned conclusions about the prevention programmes, little is known about the possible cultural effects of the dissemination of the preventive programmes to different countries.

LQ was originally a preventive programme where the overarching idea was to help young people cope with difficulties in their lives, free from drugs and violence. Today, in the LQ curriculum SEL, character education, service-learning, and violence and substance abuse prevention are emphasized (Lions Clubs International, 2013b). According to the age group of pupils three LQ programmes are available. Skills for Growing is for pre- and elementary school pupils, Skills for Adolescence is for middle school pupils and Skills for Action is targeted at teenagers. The goals of each programme are similar, in other words, all LQ programmes are designed to help pupils develop their behaviour and skills to become healthy and capable adults (Lions Clubs International, 2013b).

LQ teacher workshops focus on positive youth development, prevention of risk behaviour, and training of social interaction skills (Lintunen, Talvio, Savolainen, \& Kuusela, 2008). In order to be trained in the LQ curriculum teachers must participate in the teachers' LQ workshop, which are always conducted by a certified trainer (Lions Clubs International, 2013b).

\section{Method}

This is a mixed method study that aimed to investigate the perceptions of local implementers concerning the Lions Quest youth development programme.

\subsection{Participants}

The participants $(n=22)$ were 7 trainers and altogether 15 country directors and other LQ administrators representing 15 different countries. Half of the participants were female. About two-thirds of the participants came from a country where LQ had been implemented for over 10 years, and one-third represented a country where LQ had been implemented during the last few years. Over $40 \%$ of the participants had over five years of experience of conducting LQ, and about $30 \%$ had one to five years of experience. About $30 \%$ were newcomers having less than one year's experience of LQ.

\subsection{Ethical considerations}

The participants were told that their responses would be analysed and reported anonymously to protect their privacy. They were also informed about the possibility of withdrawing both their participation and their data from this study at any time, without advance warning or explanation. None of the participants withdrew their responses.

\subsection{Design and Materials}

The data were collected at the LQ European meeting in January 2013. The participants were not informed about the data collection beforehand to prevent any participants from preparing for it, such as studying the official goals. The questionnaire consisted of multiple-choice questions about the respondents' background and open-ended questions about the perceived goals. The participants were asked what country they were from, how many years they had been involved in LQ and what their LQ duty was (trainer, senior trainer or country director/administrator). In addition, they were asked to estimate how many hours were given to the LQ teachers' workshop in their country. The data about the goals were asked using two questions: "What are the four most important things teachers learn from LQ workshop organized in your country?" and "What are the four most important things pupils learn from LQ lessons and trained LQ teachers?" Altogether 82 answers were given to the question regarding the goals of the 
teacher workshop. Of them, 14 answers could not be categorized because they represented an unusual or unique view, or the answer could not be understood at all, or no answer was given. To the question concerning the pupils' $L Q$ goals, 78 answers were given of which 10 could not be categorized for the above-mentioned reasons. Hence, both the open-ended questions of the questionnaire produced 68 answers that could be analysed.

\subsection{Analyses}

The open-ended questions on the LQ implementers' perceptions were analysed by using an abductive strategy. Beginning with the first unit identified in the answer, a classification procedure was undertaken whereby one or more categories were developed to capture the meanings contained in each answer. The model for classification was developed mostly on the basis of the data. The analysis first produced eight categories for both answers of the two questions. After refining the categories, four final categories for the answers of the goals of teachers' workshop and three final categories for the answers of pupils' LQ goals were formed.

During the process of classification and redefinition of the categories, peer debriefing among the authors was utilized (Miles \& Huberman, 1994) in an effort to achieve consensual validation and thereby increase the credibility of the analysis and the interpretation of the data. The first author consulted the other author regularly to discuss any difficulties that arose during the analysis or to obtain a second perspective on the appropriateness of the classification for specific units of the formulation of specific categories and subcategories. During the peer debriefing, when our perspectives differed, discussion was used to achieve consensus.

To condense the information of the background variables we produced three classes for experience, 0-1 years, 15 years and over 5 years. We also divided the countries that the participants represented into two classes, less than five years or over five years of LQ implementation in their country. Finally, the hours of the teachers' workshop were condensed into three classes: less than 10 hours, 11-16 hours and over 16 hours. Thus, the background variables were participant's gender, participant's LQ experience, participant's LQ role/position trainer, senior trainer or administrator), the length of the LQ history in the country the participant represents (new country or old country), and the length of the teachers' LQ workshop in the country the participant represents.

\section{Results}

\subsection{Qualitative results}

Results are presented by organizing them according to the order of the official goals of the teachers' LQ workshop (Lions Clubs International, 2005) and the goals of the LQ programme for the pupils (Lions Clubs International, 2011).

\subsubsection{The perceived goals of teachers' Lions Quest (LQ) workshop}

The classification of the answers about the perceived goals of the teachers' LQ workshop (research question 1) produced four categories: Learning environment, Teacher development, Implementing LQ, and Social and emotional learning (SEL).

\subsubsection{Learning environment}

Almost one third of the answers regarding the goals of teachers' LQ workshop belonged to the Learning environment category. "To take group dynamics seriously", "How to establish a good learning environment" or "Building trust among students" were typical answers in this category. Sometimes positive relationships were seen as building material for a good learning environment by formulating the goal as "How to create a relationshipcentred learning environment". This category matched quite well with the teachers' LQ workshop goal: "To examine the ways a classroom and the school-wide learning community can support the development of capable, healthy young people of strong character." 


\subsubsection{Teacher development}

Answers including the idea of teacher development were quite frequent among the participants. Altogether about 20 per cent of the answers belonged to this Teacher development category including the idea that the teachers in the workshop learn something new by experiencing the programme, for example, about showing respect in the classroom, "They recognize and respect children in a deeper way" or about the teacher's role, "Not being the main character". One of teachers' LQ workshop goals is "to understand and experience the programme components and materials". It can be concluded that the participants' answers in this category matched quite well with this goal.

\subsubsection{Implementing $L Q$}

About one-fifth of the answers constituted the category Implementing the $L Q$. This category included the idea of learning to implement the programme in the classroom and conducting a LQ lesson, for example: "Ideas to organize the lessons" or how to use the provided material, for example: "How to use LQ material" and "How to use the lesson design". The answers in this categorywere similar to the teachers' LQ workshop goal: "Use program components and materials."

\subsubsection{Social and emotional learning (SEL)}

Social and emotional learning (SEL) was a big category in this study representing almost one-third of the 68 answers concerning the goals of the workshop for the teachers. "How to manage SEL" and "SEL strategies" were quite typical answers showing that the definition $S E L$ was familiar to these responders. "Make students believe in themselves" and "To give children the sense of self-esteem (and motivations)" were examples of the answers that described just one element of the SEL. Communication was mentioned as a tool to manage emotions. The teachers' LQ workshop goal: "To learn how Lions Quest programmes address the key elements of positive youth and prevention, including the integration of social and emotional learning, prevention, character development, and service-learning", resembles the content of the participants' answers stressing the importance of individual life skills.

\subsubsection{Additional results}

Service learning was mentioned by only two of the participants, and further, prevention was not mentioned in any of the participants' answers as a goal of the teachers' LQ workshop. It can be concluded that the answers partly matched the official goal focusing on SEL skills and character development and not on service learning or prevention.

\subsubsection{The perceived goals of pupils' $L Q$}

The answers about the perceived goals of LQ for pupils (research question 2) were classified into three categories: Relationship skills, Self-awareness and self-management of SEL, and Responsible decision making.

\subsubsection{Relationship skills}

The biggest category of the perceived goals of the pupils' LQ goals was Relationship skills. Over half of the answers belonged to this category. "How to live together with others" and "How to build relationships" were typical answers in this category, as well as individual words such as "Respect" or "Consideration". The answers in this category matched well with the pupils' LQ goal: "To engage students, families the school and community members in creating a learning community of caring relationships, high expectations for positive behaviours, and meaningful involvement."

\subsubsection{Self-awareness and self-management of SEL}

The participants' answers regarding the goals of LQ for the pupils included suggested skills about self- awareness and self-management comprising a category namely Self-awareness and self-management of SEL. Over one fourth of the answers belonged to this category. In addition to direct expression of self-awareness some participants put it another way: "I have a free will and willingness and I am somebody" or "To feel a very important person" or "Be 
conscious about their own life behaviour". Self-management was seldom expressed separately but usually together with other SEL skills, for example, "How to be well aware and able to communicate and manage emotions". Overall, the pupils' LQ goal: "To provide opportunities for young people to learn the essential skills needed to lead healthy and productive lives", was in line with the participants' answers in this category.

\subsubsection{Responsible decision making}

Responsible decision making, one of the elements of SEL was mentioned directly in seven answers. In addition, six participants stressed in their answer "Responsibility", which was categorized into this category. Altogether, one fifth of the given answers belonged to this category. Pupils' LQ goal: "To strengthen young people's commitments to their families, positive peers, schools, and communities" included the idea of these answers stressing responsibility in a living environment and community.

\subsubsection{Additional results}

Answers matching to pupils' LQ goal: "To engage young people in the practice of good citizenship through cooperation and service to others", were not given. However, "Volunteerism" was mentioned once in perceived goals of LQ for pupils. In addition, the pupils' LQ goal "To promote a safe, healthy approach to life, free from the harm of alcohol and other drug use" did not show up in the answers. Only one comment about alcohol or other drugs was mentioned: "Staying away from drugs". Prevention was mentioned directly only once, but there were three other comments on building assertiveness, for example, "To resist the pressure by saying no". Such responses were classified into the Self-awareness and self-management of SEL category.

\subsection{Quantitative results}

The Kruska-Wallis test was performed to analyse the possible relationships between the background variables and the above-mentioned categories formed from the participants' answers. No statistical relationships were found in the answers between gender, participants' LQ experience or their LQ role/position. In addition, the length of the teachers' workshop or the length of the LQ history in the country the participant represented did not affect the answers.

\section{Discussion}

Overall, the LQ implementers' answers were quite similar in different countries. In terms of their perceptions on both the goals of the teachers' workshop and the goals of the LQ programme for the pupils there was not much variation. The experience, gender or the role as a LQ implementer (trainer or administrator) were not related to the answers. In addition, the participants' country or the length of the history of the LQ activity in their country did not have an effect on the answers. Further, the length of the teachers' LQ workshop in their own country did not influence the participants' perceptions on the goals of the teachers' LQ workshop.

Most participants mentioned such ideas as creating a good learning community, socio-emotional learning (SEL), and learning to use the material and conduct a LQ lesson. This indicated that the participants' perceptions of the teachers' $L Q$ goals were quite similar to the official goals. However, no answers mentioned prevention of alcohol or drugs. In addition, service learning or strengthening citizenship or participation in society were mentioned in only two participants' answers concerning perceptions on the goals of the teachers' LQ workshop.

All participants' answers about pupils' LQ goals usually included mentions about engaging pupils in order to create a learning community of caring relationships, learning skills for life, and strengthening the commitments to their peers and families. Thus, from this point of view, the perceptions of the participants and the official goals of pupils' LQ goals were similar. However, strengthening citizenship or participation in society was not mentioned. Also, references to prevention were rare, since it was directly mentioned only once. On the other hand, a few answers included the idea of learning to be assertive, which reflected LQ's idea of the approach to prevention.

It would seem that the process of LQ implementation was quite successful in maintaining the original goals in the LQ curricula: the perceptions of LQ goals and the official LQ goals were similar internationally. It thus appeared that there were no big differences from country to country. However, in this study we did not investigate how the 
implemented LQ was conducted or how the goals were carried out in practice in schools by local teachers. There may be differences across countries when it comes to actual practices.

It is possible, however, that the similarity between official goals and the perceptions of the LQ goals in all countries indicates that cultural circumstances may not have been taken into account when implementing LQ. However, LQ has a long history in many countries and it might be difficult to acquire local resources and participants for the courses year after year if LQ was considered too foreign or strange by local schools. We believe that it is a question of a balance between local needs and LQ official goals which do not, fortunately, have to be contradictory. It is likely that to find the best ways of implementing the LQ programme calls for considerable joint planning. Further, international training may be needed in order to create a common understanding of the LQ benefits in each country.

Partly, however, the perceptions of LQ and the official goals were different, although participants did not mention substance abuse prevention in their perceptions of the goals of LQ. It is possible that the trend or development of the preventive programmes in general can be seen here. As said before, according to the modern recommendations of preventive programmes in schools, SEL should be included instead of, for example, facts-only or fear appeals education. Presumably, the participants considered that substance abuse prevention of any kind was somewhat unimportant. Some of the participants mentioned assertiveness as one goal of the LQ goal, and this in fact reflects quite well one way in which SEL might prevent substance abuse. It is possible that the participants did not explicitly mention substance abuse prevention as they believed that SEL training and assertiveness automatically helps in preventing drug and alcohol misuse. When students learn to be assertive, it may become easier to refuse something that is obviously harmful.

Service learning was another issue that was hardly ever mentioned. This might reflect cultural differences in the countries represented. Service learning including volunteer work is stressed in the United States but not in European welfare states. In the Nordic countries, for example, the role of society is different from that in the U.S., meaning that municipalities and the state take care of tasks that are organized by volunteers in the U.S. Hence, the importance of the topic might not be seen as important in the implementing countries and therefore might easily be left out.

It would be interesting to know what the outcomes of LQ are, i.e. whether the teachers benefit from the LQ teacher workshop and if they do, how they apply the skills studied during LQ. Naturally, research on the benefits of LQ for pupils would also be a very important research topic. Even though the outcomes of SEL seem quite clear, rigorous research is still needed to evaluate such international SEL programmes as LQ. Our study is, in fact, only a start towards a more systematic inquiry.

\section{Acknowledgements}

This study was partially funded by the project RYM Indoors Environment 462054 of the Finnish Funding Agency for Technology and Innovation. We would also like to thank Lions Clubs International Foundation and Ulla Savolainen for their contribution to this manuscript.

\section{References}

Ajzen, I., \& Fishbein, M. (1980). Understanding attitudes and predicting social behaviour. Englewood Cliffs, NJ: Prentice Hall.

Bandura, A. (1998). Personal and collective efficacy in human adaptation and change. In J.G. Adair, D. Belanger, \&

K.L. Dion (Eds.), Advances in psychological sciences. Vol 1: Social, personal and cultural aspects (pp. 51-71). Hove: Psychology press.

Brock, L. L., Nishida, T. K., Chiong, C., Grimm, K. J., \& Rimm-Kaufman, S. E. (2008). Children's perceptions of the classroom environment and social and academic performance: A longitudinal analysis of the contribution of the responsive classroom approach. Journal of School Psychology, 46(2), 129-149. 
Catalano, R. F., Berglund, M. L., Ryan, J. A. M., Lonczak, H. S. \& Hawkins, J. D. (2004). Positive youth development in the United States: Research findings on evaluations of positive youth development programs. The Annals of the American Academy of Political and Social Science, 591: 98-124.

Collaborative for academic, social and emotional learning. (2013). Mission and vision. Retrieved from http://casel.org/about-us/mission-vision/

Collaborative for academic, social and emotional learning. (2002). 10 guidelines to effective SEL practice. Retrieved from http://casel.org/wp-content/uploads/GuidelinesAug02.pdf

Crick, N. R. \& Dodge, K. A. (1994). A review and reformulation of social information-processing mechanisms in children's social adjustment. Psychological bulletin, 115(1): 74-101.

Cuijpers, P. (2002). Effective ingredients of school-based drug prevention programs: A systematic review. Addictive Behaviors, 27(6), 1009-1023.

Durlak, J. A., Weissberg, R. P., Dymnicki, A. B., Taylor, R. D., \& Schellinger, K. B. (2011). The impact of enhancing students' social and emotional learning: A meta-analysis of school-based universal interventions. Child Development, 82(1), 405-432.

Durlak, J. A., \& Wells. A. M. (1997). Primary prevention mental health programs for children and adolescents: A meta-analytic review. American Journal of Community Psychology, 25(2): 115-152.

Elbertson, N.A., Brackett, M.A., \& Weissberg R.P. (2010). School-based social and emotional learning (SEL) programming: current perspectives. In A. Hargreaves, A. Lieberman, M. Fullan, \& D. Hopkins (Eds.), Second international handbook of educational change (pp. 1017-1032). Dordrecht: Springer.

Elias, M. J., Zins, J. E., Weissberg, T. P., Frey, K. S., Greenberg, M. T., Haynes, N. M., Kessler, R., SchwabStone, M. E., \& Shriver, T. P. (1997). Promoting social and emotional learning: Guidelines for educators. Alexandria, VA: Association for Supervision and Curriculum Development.

Greenberg, M. T., Weissberg, R. P., O’Brien, M. U. Zins, J. E., Fredericks, L., Resnik, H., \& Elias, M. J. (2003). Enhancing school-based prevention and youth development through coordinated social, emotional, and academic learning. American Psychologist, 58(6): 466-474.

Haggerty, R. J., Sherrod, L. R., Garmezy, N., \& Rutter, M. (1994). Stress, risk, and resilience in children and adolescents: Processes, mechanisms, and interventions. Cambridge: Cambridge University Press.

Hawkins, J.D. (1997). Academic school performance and school success: sources and consequences. In R.P. Weissberg, T.P. Gullotta, R.L. Hampton, \& B.A. Ryan (Eds.), Healthy child 2010: Enhancing children's wellness (pp. 278-305).Thousand Oaks, CA: Sage Publications.

Jessor, R. (1992). Risk behavior in adolescence: A psychosocial framework for understanding and action. Journal of adolescent Health, 12(4): 374-390.

Kanfer, F. H., \& Goldstein, A. P.(1991). Helping people change. New York: Pergamon Press.

Lintunen, T., Talvio, M., Savolainen, U., \& Kuusela, M. (2008). Collaboration Strengthens Social and Emotional Learning Programming in Finland. Advances in SEL Research (American Educational Research Association), 1(2), 6-7.

Lions Clubs International. (2005). Lions Quest: Skills for growing and skills for adolescence. 2- and 3-day K8/SFG/SFA workshop modularized trainer's manual. Oak Brook, IL: Author. Lions Clubs International. (2011). Skills for adolescence. Out of school time. Oak Brook, IL: Author

Lions Clubs International (2013a). International overview. Retrieved from http://www.lionsquest.org/international.php

Lions Clubs International (2013b). Program overview. Retrieved from http://www.lionsquest.org/progoverview.php

Mayer, J.D., \& Salovey. P. (1997). What is emotional intelligence? In P. Salovey and D.J. Sluyter (Eds.), Emotional development and emotional intelligence (pp. 3-31). New York: Basic Books.

Miles, M. B., \& Huberman, A. M. (1994). Qualitative data analysis: An expanded sourcebook. (2nd ed). Thousand Oaks: Sage. 
Payton, J. W., Wardlaw, D. M., Graczyk, P. A., Bloodworth, M. R., Tompsett, C. J., \& Weissberg, R. P. (2000). Social and emotional learning: A framework for promoting mental health and reducing risk behavior in children and youth. Journal of School Health, 70(5): 179-185.

Prevention First. (2008). Ineffectiveness of fear appeals in youth alcohol, tobacco and other drug (ATOD) prevention. Springfield, IL: Author.

Rimm-Kaufman, S. E. (2006). Social and academic learning study on the contribution of the responsive classroom ${ }^{\circledR}$ approach. Retrieved from http://www.responsiveclassroom.org/sites/default/files/pdf_files/sals_booklet_rc.pdf

Rimm-Kaufman, S. E., Fan, X., Chiu, Y., \& You, W. (2007). The contribution of the responsive classroom approach on children's academic achievement: Results from a three year longitudinal study. Journal of School Psychology, 45(4), 401-421.

Thomas R.E., McLellan J., \& Perera R. (2013). School-based programmes for preventing smoking. Cochrane Database of Systematic Reviews 4: Art. No.: CD001293.

Wells, J., Barlow, J., \& Stewart-Brown, S. (2003). A systematic review of universal approaches to mental health promotion in schools. Health Education, 103(4): 197-220.

Zins, J. E., Weissberg, R. P., Wang, M. C., \& Walberg, H. J. (Eds.). (2004). Building academic success on social and emotional learning: What does the research say? New York: Teachers College Press. 